\title{
Assessment of Blood Antioxidant Defense and Oxidative Stress in Colorectal Carcinoma Patients Undergoing Capecitabine and Oxaliplatin Combined with Bevacizumab Treatment
}

\author{
Naima Badid ${ }^{1}$, Hafida Merzouk ${ }^{2}$, Amine Charef ${ }^{3}$
}

${ }^{1} \mathrm{PhD}$ of Clinical Nutrition, Physiopathology and Biochemistry of Nutrition Laboratory (Ppabionut), Department of Biology, Faculty of Sciences of Nature and Life \& Sciences of the Earth and the Universe, University of Tlemcen, Algeria

$2 \mathrm{PhD}$ of Physiology, Professor, Physiopathology and Biochemistry of Nutrition Laboratory (Ppabionut), Department of Biology, Faculty of Sciences of Nature and Life \& Sciences of the Earth and the Universe, University of Tlemcen, Algeria

${ }^{3} \mathrm{PhD}$ of Oncology, Oncology Service, Établissements Public Hospitalier (EPH), Maghnia, Algeria

Type of article: Original

\begin{abstract}
Background: Blood oxidant profile affects tumor cell eradication in cancer patients undergoing thermotherapy. Objective: The study objectives were the determination of the blood oxidant/antioxidant balance in colorectal cancer (CRC) before and after the XELOX regimen combined with Bevacizumab, and also the effect of treatment on the oxidative stress markers during the first cycle of chemotherapy.

Methods: In this case-control study, 50 healthy controls and 41 colorectal patients were recruited at Popular Hospital Establishment and Avicène Medical Clinic (Maghnia city, Algeria) during 2019. Blood samples were collected from participants before and after treatment. To determine the fluctuations of redox status vis-à-vis of treatment, levels of oxidant and antioxidant parameters were measured using spectrophotometry. Data were analyzed using independent samples t-test and Pearson's correlation coefficients.

Results: The obtained results highlighted the presence of oxidative stress in CRC cases compared to controls. In CRC, high levels in malondialdehyde $(3.06 \pm 0.65 \mu \mathrm{mol} / \mathrm{L}, \mathrm{p}=0.090)$, superoxide anion $(8.38 \pm 0.21 \mu \mathrm{mol} / \mathrm{L}$, $\mathrm{p}=0.478)$, carbonyl proteins $(0.453 \pm 0.11 \mathrm{nmol} / \mathrm{mg}$ protein; $\mathrm{p}=0.292)$, and peroxynitrite $(12.8 \pm 4.27 \mu \mathrm{mol} / \mathrm{mL}$, $\mathrm{p}=0.093)$ with significant difference in nitric oxide value $(26.07 \pm 5.50 \mu \mathrm{mol} / \mathrm{L} ; \mathrm{p}=0.0001)$ were depicted before treatment and, and low total activities of superoxide dismutase $(37.81 \pm 0.07 \mathrm{U} / \mathrm{gHb} ; \mathrm{p}=0.0001)$ and catalase $(29.33 \pm 4.99 \mathrm{U} / \mathrm{gHb} ; \mathrm{p}=0.0001)$ with a decrease of glutathione $(2.92 \pm 0.9 \mathrm{mmol} / \mathrm{L} ; \mathrm{p}=0.0001)$ concentration were recorded. After treatment, malondialdehyde $(1.59 \pm 0.11 \mu \mathrm{mol} / \mathrm{L} ; \mathrm{p}=0.003)$, superoxide anion $(7.68 \pm 0.17 \mu \mathrm{mol} / \mathrm{L}$; $\mathrm{p}=0.003)$, and carbonyl proteins $(0.311 \pm 0.02 \mathrm{nmol} / \mathrm{mg}$ protein; $\mathrm{p}=0.024)$ rates decreased at the opposite of nitric oxide $(57.46 \pm 9.69 \mu \mathrm{mol} / \mathrm{L} ; \mathrm{p}=0.001)$ and peroxynitrite $(20 \pm 3.82 \mu \mathrm{mol} / \mathrm{mL} ; \mathrm{p}=0.002)$ levels, which increased markedly alike the activities of superoxide dismutase $(379.54 \pm 0.66 \mathrm{U} / \mathrm{gHb} ; \mathrm{p}=0.05)$ and catalase $(131.92 \pm 5.83$ $\mathrm{U} / \mathrm{gHb} ; \mathrm{p}=0.0001)$, and reduced glutathione level $(16.11 \pm 0.57 \mathrm{mmol} / \mathrm{L} ; \mathrm{p}=0.0001)$ raised significantly.

Conclusion: Limiting the efficiency of drug treatment inhibits the eradicating effect of high blood levels of nitric oxide and peroxynitrite for tumor cells, where cancer patients are nonresponsive to chemotherapeutic treatment. Blood oxidant/antioxidant levels should be an effective guideline for directing the response to cancer treatments, especially the risk of resistance to anti-tumor drugs. Redox homeostasis, which is linked to nutritional profile and lifestyle, should be included in medical check-ups to achieve a better prediction of treatment response.

Keywords: Antioxidants; Oxidative stress; Colorectal cancer; Chemotherapy
\end{abstract}

Abbreviations / Acronyms:

ROS: Reactive Oxygen Species CRC: Colorectal Cancer; MDA: Malondialdehyde; $\mathbf{O}_{2}{ }^{\circ}$ : Superoxide Anion; CP: Carbonyl Proteins; NO": Nitric Oxide; ONOO": Peroxynitrite; SOD: Superoxide Dismutase; CAT: Catalase; GSH: Reduced Glutathione; BEVA: Bevacisumab; BT: Before Treatment; AT: After Treatment.

\section{Corresponding author:}

Dr. Naima Badid, Physiopathology and Biochemistry of Nutrition Laboratory (Ppabionut), Department of Biology, Faculty of Sciences of Nature and Life \& Sciences of the Earth and the Universe, University of Tlemcen, Algeria. Tel: +213.541031666, E-mail: badidnaima@gmail.com

Received: December 09, 2020, Accepted: February 27, 2021, Published: March 2021

Ethics approval: General Directorate for Scientific Research and Technological Development (DGRSDT) in Algeria (Ref: I02020090081)

(C) 2021 The Authors. This is an open access article under the terms of the Creative Commons Attribution-NonCommercialNoDerivs License, which permits use and distribution in any medium, provided the original work is properly cited, the use is non-commercial and no modifications or adaptations are made. 


\section{Introduction}

Colorectal cancer (CRC) incidence rates vary widely. More than 1.8 million new CRC cases and 881,000 deaths were estimated worldwide in 2018. It ranks third in incidence and second in mortality (1). Health problems can be considered a marker of socioeconomic development. In developing countries, CRC incidence tends to rise homogeneously with increasing Human Development Index (2). Despite advanced CRC diagnosis and treatment tecniques, the CRC mortality rate is constantly high (3). This increased incidence indicates the influence of dietary profile, lifestyle factors, and obesity, while the mortality declines observed in more developed countries reflect improvements in survival through the adoption of best practices in cancer treatment (4). Actually, CRC treatment encompasses surgery, radiation and chemotherapy. However, the efficacy of these treatments varies across different cancer cells (5). Surgery, combined with chemotherapy and/or radiotherapy, is the main CRC therapy strategy, which is efficient in the early stage of CRC; however, it is poorly efficient in the advanced stage of CRC with metastasis (6). There are several pathological factors, including reactive oxygen species (ROS), which are known to be mitogenic, capable of tumor promotion (7-10), and involved in the process of cancer initiation and progression (11-15). Note that, hypermethylation of the gene promoter regions and oxidative damage to nuclear DNA are the main mechanisms in the initial stages of colorectal carcinogenesis $(10,11)$. It is admitted that an accurate regulation of ROS production and scavenging is capital for ensuring cellular homeostasis. Therefore, various enzymatic and non-enzymatic processes can lead to the conversion of highly reactive molecules to less reactive ones. The detoxification from ROS in the cytoplasm, or in the mitochondria, is the main purpose of these antioxidant systems (16). Oxidative stress is an imbalance between blood oxidants and antioxidants. It reflects an abnormal accumulation of ROS, which has long been associated with several disease processes, including cancer. Oxidants are integrated into numerous cellular processes by physiologically transporting signals, as a second messenger or pathologically oxidizing lipids, proteins, and DNA $(12,16)$. Furthermore, oxidative stress is known to influence the response of these patients to therapy. Moreover, the body's defense mechanisms would ensure antioxidant defenses and try to minimize the damage, adapting itself to the above stressful situation. The undertaken drug regimen for CRC patients is applied in compliance with the schemes by combining a dual cytotoxic therapy "Xelox" (oxaliplatin and or capecitabine) to a targeted agent Bevacizumab (BEVA), also called Avastin, as standard first-line therapy for metastatic patients with CCR. Chemotherapy drugs, including "Xelox," act on the cell division mechanisms. In that, targeted therapies, such as BEVA, blocks specific mechanisms of cancer cells (17). Due to the emergence of drugresistant tumor cells, successful cancer treatment has remained challenging. Despite continuous research on chemotherapeutic agents, different mechanisms of resistance, depending on ROS profile, have become a major pitfall in cancer chemotherapy. The targeted objectives of this study are first to determine the redox status in newly diagnosed CRC patients compared to healthy controls and second to evaluate the significance of the effect of the protocol Xelox/BEVA therapy on the oxidative stress markers during the first cycle of chemotherapy.

\section{Material and Methods}

\subsection{Subjects and inclusion criteria}

A total of 41 newly diagnosed CRC patients were recruited in the department of gastrology and oncology at Popular Hospital Establishment and a medical clinic (Maghnia city, Algeria) during 2019 after obtaining their written consent. They had not undergone any prior treatment for their cancer. The subjects were in the age range of 45-81 years. Their body mass index (BMI, $\mathrm{kg} / \mathrm{m}^{2}$ ) was obtained by dividing weight (in kilograms) by height (in meters) squared and used as an index of body fat. Fifty healthy participants, aged from 46 to 70 years, were selected as controls. They all had a BMI under $25 \mathrm{~kg} / \mathrm{m}^{2}$ (normal weight). Participants were asked to complete a questionnaire with epidemiologic information containing demographic and lifestyle factors, personal and medical history, and family history of CRC.

\subsection{Exclusion criteria}

Patients with any acute or chronic inflammatory disease, such as diabetes mellitus, liver disease, thyroid disease, nephrotic syndrome, and/or known malignancy, and those who were using vitamin complements were excluded from the study. None of the controls had an anterior history of CRC and other cancer-related diseases.

\subsection{Blood Sample Collection}

Blood specimens, from both healthy volunteers and CRC patients, were collected in heparinized tubes $(10 \mathrm{~mL})$. After centrifugation, plasma was separated aseptically for biochemical parameters and oxidative stress markers. The remaining erythrocytes were washed three times in isotonic saline $(0.85 \mathrm{~g} / 100 \mathrm{~mL})$ to ensure complete removal of plasma, leucocytes, and platelets. The washed red blood cells were undergone hemolysis by the addition of sterile 
distilled ice-cold water, stored in a refrigerator at $4^{\circ} \mathrm{C}$ for $15 \mathrm{~min}$. Then, cell debris was pulled by centrifugation $(2,000 \mathrm{~g} / 15 \mathrm{~min})$. The hemolysates were used for the analysis of various antioxidants.

\subsection{Reactive oxygen and nitrogen species determination (ROS)}

To evaluate lipid peroxidation, erythrocyte malondialdehyde (MDA) concentrations, were assayed by the reaction of MDA with thiobarbituric acid (Sigma Aldrich kit, Sigma Aldrich St. Louis, MO). As markers of protein oxidation, erythrocyte carbonyls proteins (CP) were estimated by 2,4-dinitrophenylhydrazine reaction with carbonyl groups (Sigma Aldrich kit, Sigma Aldrich St. Louis, MO). Plasma superoxide anion $\left(\mathrm{O}_{2}{ }^{\circ}\right)$ concentration was determined using the reduction of nitrobluetetrazolium NBT in monofarmazan by $\mathrm{O}_{2}{ }^{-}(18)$. The level of plasma nitric oxide $\left(\mathrm{NO}^{\circ}\right)$ was measured using the colorimetric method of Griess reaction (Sigma Aldrich kit, Sigma Aldrich St. Louis, $\mathrm{MO}$ ). Plasma peroxynitrite (ONOO-) concentration was determined by the ability of peroxynitrite to nitrate phenol at $37^{\circ} \mathrm{C}$, leading to the formation of nitrophenol according to the method of VanUffelen et al. (19).

\subsection{Antioxidants determination}

Erythrocyte reduced glutathione (GSH) concentration was measured using a colorimetric method based on the use of the 5,5-dithiodis-2-nitrobenzoic acid (DTNB) molecule with GSH, which releases the thionitrobenzoic acid (TNB), (Sigma Aldrich kit, Sigma Aldrich St. Louis, MO). Concerning enzyme activities, we first measured catalase activity based on the reaction of the enzyme with methanol in the presence of an optimal concentration of $\mathrm{H}_{2} \mathrm{O}_{2}$. The resulted formaldehyde is determined with 4-amino-3-hydrazino-5-mercapto-1,2,4-triazole, as the chromogen, according to the Cayman kit (Cayman Chemical Company, Ann Arbor, MI). The activity of erythrocyte superoxide dismutase (SOD) was determined by measuring the dismutation of superoxides radicals generated by xanthine oxidase and hypoxanthine according to the Cayman Chemical Assay kit's instruction (Cayman Chemical Company, Ann Arbor, MI).

\subsection{Statistical Analysis}

We presented data in the form of means \pm standard deviations (SD). Independent samples t-test was used to evaluate the statistical significance of differences between control subjects and CRC patients before and after the treatment. The statistical analysis was evaluated and strengthened using Pearson's correlation coefficients.

\subsection{Ethics of research}

Informed written consent has been obtained from each participant before recruitment. This research was supported by the General Directorate for Scientific Research and Technological Development (DGRSDT) in Algeria, as a part of a CNEPRU (PRUF) project carrying the code: I02020090081.

\section{Results}

\subsection{Population characteristics}

According to this study, the subjects were in the age range of 46-81 years. The age of cases varied from $57.62 \pm 7.81$ years for controls and 59.24 \pm 9.46 years for patients. Relevant difference $(p<0.001)$ in BMI was underlined between the two groups. The data showed that CRC patients were more likely than controls to have no family history of CRC. The drug regimen consisted of Xelox protocol (Capecitabine + Oxaliplatin) for non-metastatic cancer and Xelox plus BEVA for metastatic cancer (Table 1). Cancerous patients were clinically categorized as stage I, II, III, and IV, grade 1,2, and 3, and infiltrative adenocarcinoma of the Lieberkuhnian type, according to the Tumor-NodeMetastases (TNM) classification. The planned treatment schedule was the oral drug capecitabine in combination with oxaliplatin plus the humanized anti-VEGF (anti-vascular endothelial growth factor) antibody BEVA. Patients had 21 days for usually 8 treatment cycles according to the following scheme: $7.5 \mathrm{mg} / \mathrm{kg}$ of BEVA and $130 \mathrm{mg} / \mathrm{m}^{2}$ of oxaliplatin (both intravenously) every 21 days on the $1^{\text {st }}$ day. Then, they took $1000 \mathrm{mg} / \mathrm{m}^{2}$ of capecitabine, twice per day, for 14 days consecutively. Finally, they took 7 days off.

Several redox status parameters were examined in CRC cases before and after chemotherapeutic treatments of different cancer stages as well as in the control group. The analysis of ROS such as erythrocyte MDA, CP, and plasma $\mathrm{O}_{2}{ }^{--}, \mathrm{NO}^{*}$ and $\mathrm{ONOO}^{-}$, were evaluated as biomarkers of oxidative/nitrosative stress before or after drug administration. The investigation of the antioxidant profile was realized via the erythrocyte SOD and CAT activities and, GSH and plasma vitamin $\mathrm{C}$ concentrations before and after treatment. The CRC case parameters before treatment (BT) were compared to healthy controls and then compared to those after treatment (AT). There was a notable difference between the redox status parameters of the control subjects and those of the patients. The results showed that erythrocyte $\mathrm{MDA}, \mathrm{CP}$, and plasma $\mathrm{O}_{2}{ }^{-}, \mathrm{NO}^{\circ}$, and ONOO- were higher in CRC patients $\mathrm{BT}$ than in 
healthy subjects, specifically for $\mathrm{NO}^{\bullet}(\mathrm{p}=0.090 ; \mathrm{p}=0.292 ; \mathrm{p}=0.478 ; \mathrm{p}=0.0001 ; \mathrm{p}=0.093)$. The study also revealed that SOD and CAT activities and GSH concentrations were markedly lower $(p=0.0001)$ in patients BT when compared with controls (Table 2). The profile of ROS and antioxidants differs in patients AT. A significant decrease in erythrocyte MDA, CP and plasma $\mathrm{O}_{2}{ }^{-}$levels were observed in CRC patients AT $(\mathrm{p}=0.003 ; \mathrm{p}=0.024 ; \mathrm{p}=0.003)$ compared to those $\mathrm{BT}$. Though, plasma $\mathrm{NO}^{*}$ and $\mathrm{ONOO}^{-}$were markedly higher $(\mathrm{p}=0.001 ; \mathrm{p}=0.002)$ in $\mathrm{CRC}$ cases AT than in CRC subjects BT. The antioxidant profile showed that AT, the SOD and CAT activities increased markedly $(\mathrm{p}=0.05 ; \mathrm{p}=0.0001)$. Moreover, GHS concentration raised significantly $(\mathrm{p}=0.0001)$ compared to the state of patients BT.

Table 1. Characteristics of control and CRC subjects. Values are means $\pm \mathrm{SD}$ or number (percentage), BMI: body mass index (weight/height $\left.{ }^{2}\right)$.

\begin{tabular}{|c|c|c|c|c|}
\hline \multicolumn{3}{|l|}{ Variables } & $\begin{array}{l}\text { Control subjects } \\
(\mathrm{n}=50)\end{array}$ & $\begin{array}{l}\text { Colorectal cancer patients } \\
(\mathrm{CRC})(\mathrm{n}=41)\end{array}$ \\
\hline \multirow{6}{*}{ Age (year) } & \multicolumn{2}{|l|}{ Means \pm SD } & $57.62 \pm 7.81$ & $59.24 \pm 9.46$ \\
\hline & \multirow[t]{5}{*}{ Age groups } & $<50$ & $7(14 \%)$ & $8(19.5 \%)$ \\
\hline & & $50-59$ & $25(48 \%)$ & $17(41.5 \%)$ \\
\hline & & $60-69$ & $15(30 \%)$ & $10(24.4 \%)$ \\
\hline & & $70-79$ & $3(6 \%)$ & $5(12.2 \%)$ \\
\hline & & $\geq 80$ & $1(2 \%)$ & $1(2.4 \%)$ \\
\hline \multirow{4}{*}{$\begin{array}{l}\text { Body mass } \\
\text { index } \\
\left(\mathrm{Kg} / \mathrm{m}^{2}\right)\end{array}$} & \multicolumn{2}{|l|}{ Means \pm SD } & $23.33 \pm 1.43$ & $23.54 \pm 5.42^{* * *}$ \\
\hline & \multirow[t]{3}{*}{ BMI groups } & $\leq 24.9$ & $46(90 \%)$ & $25(61 \%)$ \\
\hline & & $25-29.9$ & $5(10 \%)$ & $10(24.4 \%)$ \\
\hline & & $\geq 30$ & - & $6(14.6 \%)$ \\
\hline \multicolumn{2}{|c|}{ Family history of CRC (\%) } & $\begin{array}{l}1^{\text {st }} \text { degree of relationship } \\
2^{\text {nd }} \text { degree of relationship }\end{array}$ & $\begin{array}{l}0 \% \\
0 \%\end{array}$ & $\begin{array}{l}0 \% \\
0 \%\end{array}$ \\
\hline \multicolumn{3}{|c|}{ Drug Regimen } & - & $\begin{array}{l}\text { Xelox protocol (only) } \\
\text { Xelox + Bevacizumab }\end{array}$ \\
\hline
\end{tabular}

The significance of the differences between two groups was determined by paired samples t-test, ${ }^{*} \mathrm{p}<0.05, * * \mathrm{p}<0.01, * * \mathrm{p}<0.001$

Table 2. Antioxidant / oxidant status in control and colorectal cancer (CRC) subjects.

\begin{tabular}{|l|l|l|l|}
\hline Variables & Controls & CRC BT & CRC AT \\
\hline Malondialdehyde $(\mu \mathrm{mol} / \mathrm{L})$ & $2.32 \pm 0.60$ & $3.06 \pm 0.65$ & $1.59 \pm 0.11^{* *}$ \\
\hline Carbonyl proteins $(\mathrm{nmol} / \mathrm{mg}$ protein $)$ & $0.318 \pm 0.16$ & $0.453 \pm 0.11$ & $0.311 \pm 0.02^{*}$ \\
\hline Superoxide anion $(\mu \mathrm{mol} / \mathrm{L})$ & $8.22 \pm 0.59$ & $8.38 \pm 0.21$ & $7.68 \pm 0.17^{* *}$ \\
\hline Nitric oxide $(\mu \mathrm{mol} / \mathrm{L})$ & $6.22 \pm 0.019$ & $26.07 \pm 5.50^{* * *}$ & $57.46 \pm 9.69^{* *}$ \\
\hline Peroxynitrite $(\mu \mathrm{mol} / \mathrm{mL})$ & $8.74 \pm 0.85$ & $12.8 \pm 4.27$ & $20 \pm 3.82^{* *}$ \\
\hline Reduced Glutathione $(\mathrm{mmol} / \mathrm{L})$ & $4.62 \pm 0.43$ & $2.92 \pm 0.96^{* * *}$ & $16.11 \pm 0.57^{* * *}$ \\
\hline
\end{tabular}

Values are presented as Means \pm SD. The significance of the differences between two groups was determined by paired samples t-test, ${ }^{*} \mathrm{p}<0.05,{ }^{* *} \mathrm{p}<0.01,{ }^{* * *} \mathrm{p}<0.001$, BT: versus Control, AT: versus BT. BT SOD: $37.81 \pm 0.07$ $\mathrm{U} / \mathrm{gHb} ; \mathrm{p}=0.0001$; CAT: $29.33 \pm 4.99 \mathrm{U} / \mathrm{gHb} ; \mathrm{p}=0.0001$; AT: SOD: $379.54 \pm 0.66 \mathrm{U} / \mathrm{gHb} ; \mathrm{p}=0.05$; CAT: $(131.92 \pm 5.83 \mathrm{U} / \mathrm{gHb} ; \mathrm{p}=0.0001$

Individual interactions between oxidative stress markers, before and after drug administration, grade and stage of CRC, highlighted interesting results. The chemotherapeutic treatment consisted of the cure "a" which is composed of Xelox and the cure "b" composed of Xelox/BEVA intended for metastatic CRC cases (Stage IV, grade III). In both sexes, MDA, CP, and $\mathrm{O}_{2}{ }^{-}$levels dropped AT with the cure "a" and "b," regardless of the grade and stage of CRC. Concentrations of $\mathrm{NO}^{\circ}$ and ONOO- revealed a significant increase AT. Antioxidant activities of SOD and CAT, and the level of GSH, for both sexes, markedly over-expressed ( $p=0.05 ; p=0.0001 ; p=0.0001$ ), nonetheless the grades and the stages of patients.

\section{Discussion}

Oxidants have long been agreed to play a crucial role in carcinogenesis. They are known to be involved in the control of various signalization networks, leading to proliferation, cancer cell survival, and malignant tumors (16, $20,21)$. In this study, more than $90 \%$ of the people diagnosed with the disease are older than 50 years. Due to no 
family history in the present study, the CRC of patients is mostly because of environmental factors acting through different mechanisms. CRC patients were clinically categorized as infiltrative adenocarcinoma of the Lieberkuhnian type. Concerning case and control comparisons, considerable and non-considerable changes were observed. An increased level of MDA was observed in CRC patients BT compared to healthy subjects. Numerous studies confirmed that an increased MDA concentration has been widely reported in various cancers. Its effect on DNA and proteins has often been assigned to as decisively mutagenic (22). After treatment, the MDA levels showed a significant decrease compared to $\mathrm{CRC}$ cases $\mathrm{BT}$, which means that Xelox/BEVA combination reduced the MDA level to minimize its harmful effects. A highly significant difference is shown between CRC cases BT and AT in MDA concentration, for both sexes. At last, there were significant positive correlations between this radical AT and BMI ( $p=0.012 ; r=+0.909)$, and stage of cancer $(p=0.016 ; r=+0.894)$. Further studies revealed that oxidized proteins have been associated with the risk of carcinogenesis and the risk of developing adenopolyps type of CRC increases with increasing the levels of oxidatively modified proteins (23). A large number of proteins have been identified as redox sensitive proteins, most of which are involved in the initiation, progress and prognosis of CRC (24). The results showed an increased concentration of $\mathrm{CP}$ in CRC cases BT than in controls. This level becomes significantly lower in patients AT where a distinct difference was observed in CP concentration compared to CRC cases BT. Xelox / BEVA regimen showed a positive impact in counteracting CP regardless of stage and grade of CRC patients, reducing their harmful effects on tissues.

Superoxide anion $\left(\mathrm{O}_{2}{ }^{-}\right)$in $\mathrm{CRC}$ cases underlined high concentrations compared to controls. On contrary, a significant decrease is detected in patients AT. The high level of $\mathrm{O}_{2}{ }^{-}$in cancer cases BT reflects an obvious redox imbalance. Note that, the adhesion of tumor cells in the microvasculature is supported by this radical via endothelial apoptosis which in turn induces the adhesion of various indispensable molecules for the tumor cells (25). A high level of SOD in patients AT is reflected in the lowering of $\mathrm{O}_{2}{ }^{-}$concentration. A marked difference in $\mathrm{O}_{2}{ }^{-}$ concentration between the $\mathrm{CRC}$ cases BT and those AT is underlined for both sexes. The used treatment revealed a concrete impact in neutralizing $\mathrm{O}_{2}{ }^{-}$, regardless of the stage and grade of CRC, thereby lessening their harmful effects on tissues. Likewise, data highlighted a significant increase in plasma $\mathrm{NO}^{\bullet}$ levels in the controls compared to CRC cases BT and after taking chemotherapy. Presumably, to inhibit the DNA synthesis, alter RNA processing and induce DNA damage, the Xelox/BEVA drug-activated anti-cancer response can be based on ROS elevation (26). Many studies showed that physiological and intermediate concentrations of NO are pro-carcinogenic, whereas supraphysiological concentrations are anti-carcinogenic $(27,28)$. According to Burke et al. (14), the effects of NO ${ }^{\circ}$ depend closely on its concentration in cancer patients. In other words, low levels of $\mathrm{NO}^{*}(<100 \mathrm{nM})$ promote increased proliferation and angiogenesis, medium levels of $\mathrm{NO}^{\bullet}(100-500 \mathrm{nM})$ promote increased invasiveness, metastasis, cytoprotection and repress apoptosis, and high levels of $\mathrm{NO}^{*}(>500 \mathrm{nM})$ promote DNA damage, oxidative, nitrosative stress, cytotoxicity and apoptosis. Our results showed an evident oxidative/nitrosative stress between healthy subjects and CRC patients, which increased in patients AT. This high level of NO* will trigger cytotoxicity and apoptosis of tumor cells with Xelox medication. The radical $\mathrm{NO}^{\bullet}$ and its derivative peroxynitrite (ONOO-) are induced via inflammation-associated carcinogenesis mechanisms, including the impaired induction of DNA, suppression of DNA repair enzymes, posttranslational modification of proteins, cell proliferation, angiogenesis, metastasis, inhibition of apoptosis, and antitumor immunity (29). There are numerous mechanisms of $\mathrm{NO}^{\bullet}$ stimulating cell proliferation, including increased mitogen-activated protein kinase pathway. A multitude of studies emphasizes that $\mathrm{NO}^{*}$ alone can induce cell death, and can be combined with several clinical anticancer drugs to enhance/sensitize their activity against a variety of human malignancies (30). A significant dissimilarity is demonstrated in plasma $\mathrm{NO}^{*}$ concentration between the CRC cases BT and those AT, for both sexes. Therefore, Xelox/BEVA have an undeniable effect on the efficiency of tumor cell death by upgrading the treatment effectiveness which depends on NO• level. However, Pearson's correlation revealed NO level BT was highly correlated to $\mathrm{NO}^{*} \mathrm{AT}(\mathrm{p}=0.001 ; \mathrm{r}=+0.992)$, and $\mathrm{NO}^{*}$ concentration AT is positively correlated to anti-cancer treatment $(\mathrm{p}=0.001 ; \mathrm{r}=+0.991)$ and BMI $(\mathrm{p}=0.001 ; \mathrm{r}=+0.894)$. Peroxynitrite profile showed an increased concentration in CRC cases BT than in controls. This level significantly increased in cancer cases AT. According to the literature, $\mathrm{ONOO}^{-}$, a potent cytotoxic oxidant, promotes cellular transformation and interacts with oxidizing kinases and transcription factors, perturbing the cellular signaling network (29). Likewise, ONOO- can form 8nitroguanine, a biomarker of inflammation-associated cancers that can damage DNA. It can set off oxidizing thiols, nitrate tyrosine residues, degrade carbohydrates, and initiate lipid peroxidation (14). A relevant difference appears in ONOO- concentration in CRC cases BT compared to CRC cases AT in both sexes and all stages and grades. The treatment with Xelox/BEVA takes the advantage of the presence of ROS to instigate and strengthen its antitumor activity. Moreover, Pearson's correlation revealed that ONOO- concentration BT is positively correlated to ONOOlevel AT ( $\mathrm{p}=0.047 ; \mathrm{r}=+0.883$ ). These findings were consistent with the literature results concerning ONOO-and 
ROS cytotoxic functions (26). Subsequently, the present study revealed that glutathione (GSH) concentrations in CRC patients BT were significantly lower than in controls. After the administration of Xelox/BEVA, GSH levels increased markedly in patients. This post-treatment increase was because drugs are conjugated with GSH through activation by glutathione-S-transferases. The consequent conjugates are simply the substrates of gammaglutamyl transferases, which launch and accelerate toxic removal (31). Therefore, GSH may be used as a predictor of the treatment response of patients with CRC. A pertinent difference in GSH concentration between the CRC BT, in both sexes, and CRC AT is expressed. Interestingly, GSH levels are higher in controls than in CRC patients BT; however, it increased in the CRC patient AT. The use of the Xelox/BEVA revealed nonresponsive to therapeutic drugs due to the increased level of GSH in patients AT. As underlined in other studies, GSH levels increased in patients, who were nonresponsive to therapeutic intervention (32). A high level of GSH can boost the rate of conjugation and detoxification of chemotherapeutic drugs, thereby lowering their efficiency. Its increase is a major contributing factor to drug resistance by binding to or reacting with them (33).

The SOD activity decreased in CRC cases BT compared to healthy controls, indicating that the consumption of the latter neutralizes ROS in cancer cases. Then, its activity in CRC patients continues to increase, which is because of the abundance of free radicals in the surrounding environment due to the impact of the used treatment. However, the significant difference in SOD activity between the CRC for both sexes BT and that in the same cases AT is highly expressed. The use of the protocol Xelox/BEVA reveals to have a pertinent effect on heightening of antioxidant profile via the elevation of the SOD activity. In parallel, CAT activity significantly decreased in CRC patients BT compared to controls. In addition, it was shown that during CRC development, the activity of CAT decreased (8). After taking Xelox/BEVA treatment, CAT activity considerably amplified, reflecting unbiased effects of anticancer medication. Indeed, low CAT activity BT was accompanied by an increased risk of CRC. Subjects with increasing CAT activity had reduced risk (34). These results are consistent with those reported in erythrocyte CAT activity BT in breast cancer (35). However, a highly significant difference is shown in CAT activity between the CRC BT and AT in both sexes. Its activity also increased AT. This increase that hinders the effect of free radicals AT may indicate a nonresponsive effect to anti-cancer treatment. Pearson's correlation revealed that CAT activity BT is negatively correlated to CAT activity AT $(p=0.002 ; r=-0.961)$. The use of Xelox regimen alone or in combination with BEVA proves to be counteracted by the increase of antioxidant CAT activity. The oxidant/antioxidant balance, behaving like a double-edged sword in the chemotherapeutic treatment of cancerous pathologies, represents a topical concern that focuses on the concept aiming at better understanding and clarifying tumor cell metabolism, including chemo-resistance to anticancer treatments. In addition to patients' consent, the enrolment of participants was not an easy task. The consumable/instrumentation resources available at the research laboratory remain limited (cell culture, flow cytometry, etc.).

\section{Conclusions}

Oxidative stress is closely linked to CRC chemotherapy treatment. Cancer cases AT showed decreased levels of MDA, CP and $\mathrm{O}_{2}{ }^{-}$reflecting treatment effect. As well as, $\mathrm{NO}^{\circ}$ and ONOO- concentrations rose to amplify the killing off Xelox regimen/BEVA leading to cancer cell death. Furthermore, the antioxidant profile of GSH, SOD, and CAT was increased after an early relapse in cancer patients, reflecting an adaptive response AT to anticancer drugs limiting their effectiveness and inducing cell resistance to cytolysis by hydrogen peroxide. Depending on these results, redox homeostasis should be an efficient guideline for directing or predicting response to chemotherapy, particularly to prevent the risk of resistance to anti-tumor drugs. Oxidant/antioxidant balance should be used in medical check-up to improve and refine the prognosis and therefore the treatment in favor of better medical management of cancer patients. The redox status is linked to lifestyle and the nutritional profile, which is related to the physiology of the patients (digestive system, hepatic assessment, and detoxification, etc.) and physical activity or event. Therefore, the sedentary lifestyle should be investigated together with the disease to achieve a better interpretation of the impact of biochemical parameters, related to the patient redox status, on the undertaken anticancer treatment.

\section{Acknowledgments:}

The authors are grateful to the Directors of the Popular Hospital Establishment and the "Avicène" medical clinic for their help in the recruitment of study subjects. All healthy volunteers are also thanked for their participation in the study.

\section{Conflict of Interest:}

There is no conflict of interest to be declared. 


\section{Authors' contributions:}

Conception or design of the work (NB), acquisition of data (NB, AC), analysis or interpretation of data (all authors), drafting and revising the manuscript (all authors), Accountable for all aspects of the work (all authors). All authors read and approved the final manuscript.

\section{References:}

1) Bray F, Ferlay J, Soerjomataram I, Siegel RL, Torre LA, Jemal A. Global Cancer Statistics 2018: Estimates of Incidence and Mortality Worldwide for 36 Cancers in 185 Countries. Ca Cancer J Clin 2018; 68(6): 394424. doi: 10.3322/caac.21492. PMid: 30207593

2) Fidler MM, Soerjomataram I, Bray F. A global view on cancer incidence and national levels of the Human Development Index. Int J Cancer 2016; 139: 2436-2446. doi: 10.1002/ijc.30382, PMid: 27522007

3) Wu R, Feng J, Yang Y, Dai C, Lu A, Li J, et al. Significance of Serum Total Oxidant/ Antioxidant Status in Patients with Colorectal Cancer. PLoS ONE 2017; 12(1). doi: 10.1371/journal.pone.0170003. PMid: 28103261, PMCid: PMC5245835

4) Arnold M, Sierra MS, Laversanne M, Soerjomataram I, Jemal A, Bray F. Global patterns and trends in colorectal cancer incidence and mortality. Gut. 2017; 66: 683 691. doi: 10.1136/gutjnl-2015-310912. PMid: 26818619

5) Chiu HY, Tay EXY, Ong DST, Taneja R. Mitochondrial dysfunction at the Center of Cancer Therapy. Antioxid Redox Sign 2020; 10; 32(5):309-330. doi: 10.1089/ars.2019.7898. PMid: 31578870

6) Meyerhardt JA, Mayer RJ. Systemic Therapy for Colorectal Cancer. New Engl J Med 2005; 352: 476-872. doi: 10.1056/NEJMra040958. PMid: 15689586

7) Kang J, Zheng R. Dose-dependent regulation of superoxide anion on the proliferation, differentiation, apoptosis and necrosis of human hepatoma cells: the role of intracellular Ca2+. Redox Rep 2004; 9(1): 37 48. doi: 10.1179/135100004225003905. PMid: 15035826

8) Veljković A, Stanojević G, Branković B, Pavlović D, Stojanović I, Tatjana C, et al. Parameters of oxidative stress in colon cancer tissue. Acta Medica Medianae 2016; 55(3): 32-37. doi: 10.5633/amm.2016.0305

9) Wang C, Shao L, Pan C, Ye J, Ding Z, Wu J, et al. Elevated level of mitochondrial reactive oxygen species via fatty acid $\beta$-oxidation in cancer stem cells promotes cancer metastasis by inducing epithelialmesenchymal transition. Stem Cell Res Ther 2019; 10:175. doi: 10.1186/s13287-019-1265-2. PMid: 31196164, PMCid: PMC6567550

10) Glei M, Latunde-Dada GO, Klinder A, Becker TW, Hermann U, Voigt K, et al. Iron-overload induces oxidative DNA damage in the human colon carcinoma cell line HT29 clone 19A. Mutat Res 2002; 519:151-61. doi: 10.1016/S1383-5718(02)00135-3

11) Halliwell B. Free radicals, proteins and DNA: oxidative damage versus redox regulation. Biochem Soc T. 1996; 24:1023-7. doi: 10.1042/bst0241023. PMid: 8968505

12) Liu RH. Health benefits of fruit and vegetables are from additive and synergistic combinations of phytochemicals. Am J Clin Nutr 2003; 78:517S-520. doi: 10.1093/ajcn/78.3.517S. PMid: 12936943

13) Takaki A, Kawano S, Uchida D, Takahara M, Hiraoka S, Okada H. Paradoxical Roles of Oxidative Stress Response in the Digestive System before and after Carcinogenesis. Cancer. 2019; 11(2). pii: E213. doi: 10.3390/cancers11020213. PMid: 30781816, PMCid: PMC6406746

14) Burke AJ, Sullivan F, Giles FJ, Glynn SA. The yin and yang of nitric oxide in cancer progression. Carcinogenesis 2013; 34(3): 503-512. doi: 10.1093/carcin/bgt034. PMid: 23354310

15) Hirata Y. Reactive Oxygen Species (ROS) Signaling: Regulatory Mechanisms and Pathophysiological Roles. Yakugaku Zasshi 2019; 139: 1235-1241. doi: 10.1248/yakushi.19-00141. PMid: 31582606

16) Idelchik MDPS, Begley U, Begley TJ, Melendez JA. Mitochondrial ROS Control of Cancer. Semin Cancer Biol 2017; 47: 57-66. doi: 10.1016/j.semcancer. 2017.04.005. PMid: 28445781, PMCid: PMC5653465

17) Kim R. Introduction, mechanism of action and rationale for anti-vascular endothelial growth factor drugs in age-related macular degeneration. Indian J Ophthalmol 2007; 55(6): 413-415. doi: 10.4103/03014738.36473. PMid: 17951895 PMCid: PMC2635982

18) Auclair C, Voisin E. Nitroblue tetrazolium reduction. In: Greenwald RA (ed) CRC handbook of methods for oxygen radical research. CRC Press, Boca Raton, FL 1985; 123-132

19) VanUffelen BE, Van der Zee J, De Kostes BM, Van Stereninck J, Elferink JG. Intracellular but not extracellular conversion of nitroxyl anion into nitric oxide leads to stimulation of human neutrophil migration. Biochem J 1998; 330: 719-722. doi: 10.1042/bj3300719. PMid: 9480881 PMCid: PMC1219196

20) Liao Z, Chua D, Tan NS. Reactive oxygen species: a volatile driver of field cancerization and metastasis. Mol Cancer 2019; 18:65. doi: 10.1186/s12943-019-0961-y. PMid: 30927919, PMCid: PMC6441160 
21) Weinberg F, Ramnath N, Nagrath D. Reactive Oxygen Species in the Tumor Microenvironment: An Overview. Cancer 2019, 11(8), 1191. doi: 10.3390/cancers11081191. PMid:31426364, PMCid: PMC6721577

22) Vadisha Bhat S, Nayak KR, Kini S, Bhandary SK, Kumari SN, Bhat SP. Assessment of serum antioxidant levels in oral and oropharyngeal carcinoma patients IJPLM. 2016; 2(1)

23) Mehrabi S, Wallace L, Cohen S, YaoX, Aikhionbare FO. Differential Measurements of Oxidatively Modified Proteins in Colorectal Adenopolyps. Int J Clin Med 2015; 6(4): 288-299. doi: 10.4236/ijcm.2015.64037. PMid: 26069854, PMCid: PMC4461072

24) Yang HY, Chay KO, Kwon J, Kwon SO, Park YK, Lee TH. Comparative proteomic analysis of cysteine oxidation in colorectal cancer patients. Mol Cells 2013; 35: 533 42. doi: 10.1007/s10059-013-0058-1. PMid: 23677378, PMCid: PMC3887873

25) Ten Kate M, Van Der Wal, Sluite W, Jeekel H, Sonneveld P, Van Eijck CHJ. The role of superoxide anions in the development of distant tumour recurrence. Brit J Cancer 2006; 95: 1497-1503. doi: 10.1038/sj.bjc.6603436. PMid: 17088916, PMCid: PMC2360748

26) Fan C, Chen J, Wang Y, Wong YS, Zhang Y, Zheng W, et al. Selenocystine potentiates cancer cell apoptosis induced by 5-fluorouracil by triggering ROS-mediated DNA damage and inactivation of ERK pathway. Free Radical Bio Med 2013; 65: 305-16. doi: 10.1016/j.freeradbiomed.2013.07.002. PMid: 23837948

27) Fukumura DS, Jain KRK. The role of nitric oxide in tumour progression. Nat Rev Cancer 2006. 6: 521534. doi: 10.1038/nrc1910. PMid: 16794635

28) Monteiro HP, Rodrigues EG, Amorim Reis AKC, Longo LSJ, Ogata FT, Moretti AIS, et al. Nitric oxide and interactions with reactive oxygen species in the development of melanoma, breast, and colon cancer: A redox signaling perspective. Nitric Oxide 2019; 89:1-13. doi: 10.1016/j.niox.2019.04.009. PMid: 31009708

29) Kundu JK, Surh YJ. Emerging avenues linking inflammation and cancer. Free Radic Biol Med 2012; 52(9): 2013-2037. doi: 10.1016/j.freeradbiomed.2012.02.035. PMid: 22391222

30) Sinha BK. Nitric Oxide: Friend or Foe in Cancer Chemotherapy and Drug Resistance: A Perspective. J Cancer Sci Ther 2016; 8(10): 244-251. doi: 10.4172/1948-5956.1000421. PMid: 31844487, PMCid: PMC6914264

31) Gaucher C, Boudier A, Bonetti J, Clarot I, Leroy P, Parent M. Glutathione: Antioxidant Properties Dedicated to Nanotechnologies. Antioxidants (Basel) 2018; 7(5): 62. doi: 10.3390/antiox7050062. PMid: 29702624, PMCid: PMC5981248

32) Gamcsik MP, Kasibhatla MS, Teeter SD, Colvin OM. Glutathione levels in human tumors. Biomarkers 2012; 17: 671-691. doi: 10.3109/1354750X.2012.715672. PMid: 22900535, PMCid: PMC3608468

33) Yoo D, Jung E, Noh J, Hyun H, Seon S, Hong S, Kim, D, Lee D. Glutathione-Depleting Pro-Oxidant as a Selective Anticancer Therapeutic Agent. ACS Omega 2019; 4(6), 10070-10077. doi: 10.1021/acsomega.9b00140. PMid: 31460099, PMCid: PMC6648603

34) Chang D, HU Zhang L, Zhang L, Zhao YS, Meng QH, Guan QB, Zhou J, Pan HZ. Association of Catalase Genotype with Oxidative Stress in the Predication of Colorectal Cancer: Modification by Epidemiological Factors. Biomed Environ Sci 2012; 25(2):156-162

35) Badid N, Baba Ahmed FZ, Merzouk H, Belbraouet S, Mokhtari N, Merzouk SA, et al. Oxidant / Antioxidant Status, Lipids and Hormonal Profile in Overweight Women with Breast Cancer. Pathol Oncol Res 2010; 16:159-167. doi: 10.1007/s12253-009-9199-0. PMid: 19731090 